Meta

Journal des traducteurs

Translators' Journal

\title{
La revue Turjumān
}

\section{Hafedh Brini}

Volume 45, numéro 3, septembre 2000

La traduction dans le monde arabe

URI : https://id.erudit.org/iderudit/002144ar

DOI : https://doi.org/10.7202/002144ar

Aller au sommaire du numéro

Éditeur(s)

Les Presses de l'Université de Montréal

ISSN

0026-0452 (imprimé)

1492-1421 (numérique)

Découvrir la revue

Citer cet article

Brini, H. (2000). La revue Turjumān. Meta, 45(3), 565-565.

https://doi.org/10.7202/002144ar

Ce document est protégé par la loi sur le droit d'auteur. L'utilisation des services d'Érudit (y compris la reproduction) est assujettie à sa politique d'utilisation que vous pouvez consulter en ligne.

https://apropos.erudit.org/fr/usagers/politique-dutilisation/
Cet article est diffusé et préservé par Érudit.

Érudit est un consortium interuniversitaire sans but lucratif composé de l’Université de Montréal, l'Université Laval et l'Université du Québec à Montréal. Il a pour mission la promotion et la valorisation de la recherche. https://www.erudit.org/fr/ 
dré un progrès scientifique, il n'est pas néanmoins révélateur d'un repli sur le passé ou d'une simple remémoration de l'histoire glorieuse et prestigieuse des ancêtres. Bien au contraire, Turjum $\_n$ est une revue scientifique, académique et internationale de la traduction et de l'interprétation. Elle est scientifique et académique, car ce sont des spécialistes et des chercheurs qui participent à la rédaction de ses numéros. Elle est internationale car, étant éditée en quatre langues - l'arabe, le français, l'anglais et l'espagnol - elle s'assure une grande diffusion à travers le monde.

Les thèmes abordés dans ses articles sont d'actualité et très divers: des méthodes d'enseignement de la traduction et de l'interprétation, aux rapports entre la linguistique et la traduction, la stylistique comparée et la traduction, à l'étude de questions spécifiques telles que la notion de fidélité en traduction, la traduction spécialisée, etc.

Turjumān a publié 14 numéros depuis 1992. Elle édite périodiquement des numéros spéciaux sur des sujets spécifiques: la traduction et la linguistique du texte (1994), la traduction littéraire (1996), la traduction dans le monde arabe (1996) et terminologie: nouvelles perspectives (1998).

En plus des articles, chaque numéro contient deux rubriques. La première recense les publications qui s'intéressent aux problèmes de traduction entre l'arabe et d'autres langues telles que le français et l'anglais. La deuxième rend compte de publications récentes à travers le monde, de revues spécialisées dans le domaine et de conférences déjà tenues ou qui seront organisées ultérieurement.

Il convient de noter, enfin, que l'École supérieure Roi Fahd de traduction publie, en plus de la revue Turjumān, un bulletin d'information qui rapporte les nouvelles de l'école, de la revue, des publications, des conférences... et même celles de la Fédération internationale des traducteurs. L'école célèbre la Journée Mondiale de la Traduction le 30 septembre de chaque année et publie un communiqué à cette occasion dans son bulletin d'information.

HAFEdH BRINI Institut Supérieur des Langues, Tunis, Tunisie

Turjumān est une revue de traduction et d'interprétation publiée deux fois par an par l'École supérieure Roi Fahd de traduction à Tanger, Université Abdelmalek Essaâdi.

En appelant sa revue Turjumān - mot arabe plutôt ancien pour désigner le traducteur - l'école témoigne déjà du grand intérêt qu'elle accorde à la traduction et aux traducteurs dans une perspective de développement. Si le mot nous rappelle surtout le dixième siècle de l'époque abbasside, où la traduction arabe a connu un grand essor et a engen- 